\title{
Venöz tromboemboli - güncel kılavuz önerileri
}

\section{Current guideline recommendations for venous thromboembolism}

\author{
Faik Altıntaş, Onur Kocadal
}

Yeditepe Üniversitesi Tıp Fakültesi Ortopedi ve Travmatoloji Anabilim Dalı, İstanbul

\begin{abstract}
Venöz tromboemboli, ortopedik cerrahi sonrası gelişebilecek en önemli komplikasyonlardan biridir. Bu komplikasyonu önlemek için farmakolojik ve mekanik profilaksi uygulanır. Dünyada birçok ülke ve bölgelerde, venöz tromboemboli riskinin en düşük seviyeye indirilmesi için hasta, uygulanan cerrahi ve uygulaması planlanan profilaksi seçeneklerine göre düzenlenen önerileri içeren kılavuzlar geliştirilmiştir. Güncel ve yaygın olarak kabul edilen kılavuzlar; American College of Chest Physicians (ACCP), American Academy of Orthopaedic Surgeons (AAOS) ve National Institutes for Health and Care Excellence (NICE) kılavuzlarıdır. Bu çalışmada, AAOS, ACCP ve NICE kılavuzlarındaki öneriler sunulmuştur.
\end{abstract}

Anahtar sözcülkler: venöz tromboemboli; profilaksi; kılavuz; artroplasti
Venous thromboembolism is one of the most important complications that may develop after orthopedic surgery. Pharmacological and mechanical prophylaxes are applied to prevent this complication. Guidelines have been developed in many countries and regions around the world to minimize the risk of venous thromboembolism, which is organized according to the patients' medical conditions, surgical alternatives and prophylaxis options. Current and widely accepted guidelines are the American College of Chest Physicians (ACCP), the American Academy of Orthopedic Surgeons (AAOS) and the National Institutes of Health and Care Excellence (NICE). In the current study, recommendations of AAOS, ACCP and NICE guidelines were presented.

Key words: venous thromboembolism; prophylaxis; guideline; arthroplasty
$\mathbf{V}$ enöz tromboemboli (VTE) kaynaklı problemler, ortopedik cerrahi ile ilişkili morbidite ve mortalitenin en önemli nedenlerinden biridir. Majör travma veya artroplasti sonrası profilaksi yapılmayan olgularda semptomatik VTE oranı \%15-30 olarak bildirilmiştir. ${ }^{[1]}$ Asemptomatik VTE'nin ise çok daha yüksek oranda görüldüğü bilinmektedir. Profilaksi alan hastalarda ise semptomatik VTE yaklaşık olarak \%1,15 oranındadır. ${ }^{[1]}$ Venöz tromboz ve emboli risk faktörleri; geçirilmiş VTE, konjestif kalp yetmezliği, hipertansiyon, variköz venlerin mevcudiyeti, kadın cinsiyet, genetik yatkınlık, ileri yaş, malignensi ve obezite olarak sıralanabilir. ${ }^{[2,3]}$ American Academy of Orthopaedic Surgeons ise sadece geçirilmiş VTE öyküsünü risk faktörü olarak değerlendirmektedir. ${ }^{[4]}$ Tromboemboli riskini etkileyen önemli parametrelerden birisi, uygulanması planlanan cerrahi girişimdir. Günümüzde VTE riskinin azaltılması için çok sayıda farmakolojik ajan geliştirilmiştir. Literatürde, risk faktörleri göz önünde bulundurularak, farmakolojik ve non-farmakolojik profilaksinin standardize edilmesi amaçlanmıştır. Hastaya uygulanacak farmakolojik profilaksi çeşidi, profilaksinin süresi, kanama riski, non-farmakolojik profilaksinin uygulama yöntemleri gibi farklı senaryolara göre, güncel literatür ışığında önerileri içeren bazı kılavuzlar yayımlanmıştır. Ortopedi ve travmatoloji alanında bu kılavuzlardan en çok kabul görenleri; American College of Chest Physicians (ACCP), American Academy of Orthopaedic Surgeons (AAOS) ve National Institutes for Health and Care Excellence (NICE) kılavuzlarıdır. Genel olarak bu kılavuzlarda sunulan öneriler, literatürdeki bilgilerin kanıt düzeyine göre sınıflandırılmıştır. Bu bölümde; ACCP, AAOS ve NICE tromboemboli kılavuzlarındaki öneriler özetlenmiştir. Bu kılavuzlarda önerilen farmakalojik profilakside kullanılan moleküller; düşük moleküler ağırlıklı heparin (DMAH), asetilsalisilik asit, düşük doz unfraksiyone heparin (DDUH), apiksaban, dabigatran, rivaroksaban, fondaparinuks ve ayarlanmış doz $\mathrm{K}$ vitamini antagonistidir (VKA). Kılavuzlardaki mekanik profilaksi yöntemleri ise; aralıklı pnömatik kompresyon cihazı (APKC) ve antiembolik çorap kullanımıdır.

- İletişim adresi: Prof. Dr. Faik Altıntaș, İçerenköy Mah. Hastane Sok. No: 4, 4/1 Ataşehir, İstanbul

Tel: 0532 - 2319984 e-posta: faltintas@yeditepe.edu.tr

- Geliş tarihi: 22 Şubat 2019 Kabul tarihi: 6 Ağustos 2019 


\section{American College of Chest Physicians Kılavuzu[1]}

Dokuzuncu ACCP kılavuzu, 2012 yılı şubat ayında yayımlanmıştır. ${ }^{[1]}$ ACCP kılavuzlarında öneriler; kuvvetli (1) ve zayıf (2) olarak sınıflandırılmaktadır. Her iki sınıftaki öneriler, kanıt düzeyine göre yüksek (A), orta (B) ve düşük (C) olmak üzere alt gruplara ayrılmaktadır. ${ }^{[5]}$

1. Total kalça artroplastisi (TKA) veya total diz artroplastisi (TDA) uygulanan hastalarda, antitrombotik profilaksi uygulanmaması; yerine, aşağıdakilerden birinin 10 ila 14 gün boyunca kullanılması önerilir: DMAH, fondaparinuks, apiksaban, dabigatran, rivaroksaban, DDUH, VKA, asetilsalisilik asit (1B) veya APKC (1C).

2. Kalça kırı̆ı̆ ameliyatı (KKA) geçiren hastalarda antitrombotik profilaksi uygulanmaması; yerine, aşağıdakilerden birinin 10 ila 14 gün boyunca kullanılması önerilir: DMAH, fondaparinuks, DDUH, ayarlanmış doz VKA, asetilsalisilik asit (1B) veya APKC (1C).

3. Majör ortopedik cerrahi uygulanan (TKA, TDA, KKA) ve tromboprofilaksi olarak DMAH verilen hastalarda; DMAH'ye ameliyattan dört saat önce veya dört saat sonra değil, 12 saat önce veya 12 saat sonra başlanması önerilir (1B).

4. TKA veya TDA uygulanan hastalarda; tedavi süresinin uzunluğuna veya birlikte APKC kullanılmasına bakılmaksızın, alternatif olarak önerilen diğer ajanlar [fondaparinuks, apiksaban, dabigatran, rivaroksaban, DMAH (2B), ayarlanmış doz VKA veya asetilsalisilik asit (2C)] yerine DMAH kullanılması önerilir.

5. KKA uygulanan hastalarda; tedavi süresinin uzunluğuna veya birlikte APKC kullanılmasına bakılmaksızın, alternatif olarak önerilen diğer ajanlar [fondaparinuks, DDUH (2B), ayarlanmış doz VKA veya asetilsalisilik asit $(2 \mathrm{C})$ ] yerine $\mathrm{DMAH}$ kullanılması önerilir.

6. Majör ortopedik cerrahi geçiren hastalar için, ameliyat sonrası dönemde sadece 10-14 gün değil, 35. güne kadar uzatılmış tromboprofilaksi önerilir (2B).

7. Majör ortopedik cerrahi geçiren hastalarda; hastanede kalış süresince bir antitrombotik ajan ve APKC ile beraber profilaksi önerilir (2C).

8. Majör ortopedik cerrahi geçiren ve artmış kanama riski olan hastalarda; farmakolojik profilaksi yerine sadece APKC kullanımı veya hiç profilaksi yapılmaması önerilir (2C).
9. Majör ortopedik cerrahi geçiren, enjeksiyonları ve APKC kullanımını reddeden hastalarda; alternatif profilaksi olarak apiksaban veya dabigatran (eğer apiksaban veya dabigatran mevcut değilse alternatif olarak rivaroksaban veya ayarlanmış VKA) kullanılması önerilir (1B).

10. Majör ortopedik cerrahi geçiren hastalarda; kanama riski veya hem farmakolojik hem de mekanik tromboprofilaksiye kontrendikasyon nedeniyle tromboprofilaksi uygulanmayan olgularda, inferior vena cava (IVC) filtresi yerleştirilmesi, tromboprofilaksi yapılmamasına üstün olması nedeniyle önerilir (2C).

11. Majör ortopedik cerrahi sonrası asemptomatik hastalar için, taburcu edilmeden önce Doppler (veya dupleks) ultrasonografi (US) taraması önerilmez (1B).

12. İmmobilizasyon gerektiren, izole bacak yaralanması olan hastalarda; farmakolojik tromboprofilaksi yerine profilaksi yapılmaması önerilir (2C).

13. Önceden VTE öyküsü olmayan, diz artroskopisi yapılan hastalar için tromboprofilaksi önerilmez (2B).

\section{American Academy of Orthopaedic Surgeons Kılavuzu[4]}

AAOS kılavuzu, 23 Eylül 2011 tarihinde Amerikan Ortopedi Akademisi Çalışma Gurubu önerileri doğrultusunda yayımlanmıştır. ${ }^{[4]}$ Elektif diz ve kalça protezi hastalarında tromboembolinin önlenmesi için önerileri içerir. Kılavuz, tavsiye derecelerini, literatürdeki çalışmaların kanıt düzeylerine göre dikkate alarak sırasıyla; güçlü, orta, kısıtlı, uzlaşı ve belirsiz olarak belirtmektedir. Kılavuzun özet bölümündeki öneriler şu şekildedir:

1. Elektif kalça veya diz artroplastisi uygulanan hastaların ameliyat sonrası rutin dupleks US ile değerlendirilmesi önerilmemektedir. (Öneri düzeyi: Güçlü)

2. Elektif kalça veya diz artroplastisi uygulanan hastalar, VTE açısından yüksek risk altındadır. Hekimlerin, bu hastalarda daha önce VTE olup olmadığını belirleyerek bu riski daha ayrıntılı değerlendirmeleri uygun olabilir. (Öneri düzeyi: Kısıtlı)

Elektif kalça veya diz artroplastisi uygulanan hastalarda, geçirilmiş VTE öyküsü dışındaki faktörlerin bu riski arttırıp arttırmadığına dair mevcut kanitlar net değildir; bu nedenle bu hastalarda rutin olarak bu faktörlerin değerlendirilmesi için lehte veya aleyhte öneride bulunulmamıştır. (Öneri düzeyi: Belirsiz) 
3. Elektif kalça veya diz artroplastisi uygulanan hastalar, kanama ve kanamaya bağlı komplikasyonlar açısından risk altındadır. Güvenilir kanıtlar olmaması nedeniyle hastalar; hemofili gibi bilinen kanama bozuklukları ile kanama ve kanama ile ilişkili komplikasyon riskini arttıran aktif karaciğer hastalığı varlığı açısından değerlendirilebilir. (Öneri düzeyi: Uzlaşı)

Mevcut kanama bozukluğu veya aktif karaciğer hastalığının varlığı dışındaki faktörlerin bu hastalarda kanama olasılığını arttırıp arttırmadığına dair mevcut kanıtlar net değildir; bu nedenle, hastanın kanama riskini değerlendirmek için bu faktörlerin göz önüne alınması önerisinde bulunulmamıştır. (Öneri düzeyi: Belirsiz)

4. Elektif kalça veya diz artroplastisi uygulanmadan önce, hastalar antiplatelet ajan kullanıyorlarsa (örn.; asetilsalisilik asit, klopidogrel) kesmeleri önerilir. (Öneri düzeyi: Orta)

5. Elektif kalça veya diz artroplastisi uygulanan ve VTE veya kanama açısından ameliyatın kendisi dışında risk altında olmayan hastalarda; VTE'nin önlenmesi için farmakolojik ajanların ve/veya mekanik kompresyon cihazlarının kullanılması önerilir. (Öneri düzeyi: Orta)

Mevcut kanıtlar, hangi profilaktik stratejinin (veya stratejilerin) optimal veya suboptimal seviyede olduğu konusunda net değildir. Bu nedenle, bu hastalara özgü profilaksi kullanımı için lehte veya aleyhte öneride bulunulmamıştır. (Öneri düzeyi: Belirsiz)

Profilaktik stratejilerin ne kadar süreyle kullanılacağına dair güvenilir kanıtların bulunmaması nedeniyle, hastalar ve hekimler profilaksi süresini beraber değerlendirmelidirler. (Öneri düzeyi: Uzlaşı)

6. Güvenilir kanıt olmaması nedeniyle, elektif kalça veya diz artroplastisi uygulanan ve daha önce VTE geçirmiş olan hastalarda farmakolojik profilaksi ve APKC kullanılmalıdır. (Öneri düzeyi: Uzlaşı)

7. Güvenilir kanıt olmadığından dolayı, elektif kalça veya diz artroplastisi uygulanan ve bilinen bir kanama bozukluğu (örn.; hemofili) ve/veya aktif karaciğer hastalığı olan olgularda VTE'nin önlenmesi için APKC kullanılmalıdır. (Öneri düzeyi: Uzlaşı)

8. Elektif kalça ve diz artroplastisi sonrası hastaların erken mobilizasyonu gerekir. Erken mobilizasyon düşük maliyetli olup, hasta için minimum risk taşır. (Öneri düzeyi: Uzlaşı)
9. Mevcut kanıtlar, nöroaksiyel (intratekal, epidural ve spinal) anestezinin venöz tromboembolik hastalık oluşumunu etkilemediğini ortaya koymakla birlikte, elektif kalça veya diz artroplastisi uygulanan hastalarda kan kaybını azaltmak için nöroaksiyel anestezi kullanılması önerilir. (Öneri düzeyi: Orta)

10. Mevcut kanıtlar, elektif kalça ve diz artroplastisi uygulanan, kemoprofilaksi kontrendikasyonu olan ve/veya bilinen rezidüel venöz tromboembolik hastalığı da olan olgularda; IVC filtrelerinin pulmoner emboliyi önleyip önlemediğine dair net bir bilgi sunmamaktadır. Bu nedenle, bu tür filtrelerin kullanılması için lehte veya aleyhte öneride bulunulmamıştır. (Öneri düzeyi: Belirsiz)

\section{National Institutes for Health and Care Excellence Kılavuzu[6]}

NICE kılavuzu, İngiltere Ulusal Sağlık ve Klinik Mükemmellik Enstitüsü tarafından 2018 yılının Mart ayında yayımlanmış en güncel kılavuzdur. ${ }^{[6]}$ Kılavuz önerileri, 16 yaş ve üstü hasta grubunda tüm cerrahi disiplinleri kapsamaktadır. Kılavuzun ortopedik cerrahi bölümü; artroplasti cerrahisinin yanı sıra travma, artroskopik cerrahi, üst-alt ekstremite cerrahisi gibi alt disiplinler için de öneriler sunmaktadır.

\section{Elektif kalça protezi}

VTE riski kanama riskinden fazla olan elektif kalça protezi ameliyatı geçiren kişilere, VTE profilaksisi uygulanmalıdır. Aşağıdakilerden biri seçilebilir:

- 10 gün boyunca DMAH, ardından 28 gün boyunca asetilsalisilik asit ( 75 veya $150 \mathrm{mg}$ ).

- 28 gün boyunca DMAH ve taburcu olana kadar anti-embolik çorap.

Elektif total kalça protezi ameliyatı geçiren erişkinlerde VTE'nin önlenmesi için rivaroksaban kullanılabilir.

Yukarıdaki seçeneklerden hiçbiri uygulanamıyorsa, apiksaban veya dabigatran eteksilat kullanılabilir.

Elektif kalça protezi ameliyatı geçiren hastalarda farmakolojik profilaksi kontrendike ise, taburcu olana kadar sadece anti-embolik çoraplar kullanılmalıdır. 


\section{Elektif diz protezi}

$>$ Elektif diz protezi ameliyatı geçiren ve VTE riski kanama riskinden fazla olan kişilere, VTE profilaksisi uygulanmalıdır. Aşağıdakilerden biri seçilebilir:

- 14 gün boyunca asetilsalisilik asit (75 veya $150 \mathrm{mg}$ ).

- 14 gün boyunca DMAH ve taburcu olana kadar anti-embolik çorap.

- Rivaroksaban.

- Yukarıdaki seçeneklerden hiçbiri kullanılamıyorsa, apiksaban veya dabigatran eteksilat.

> Elektif diz protezi ameliyatı geçiren olgularda, farmakolojik profilaksi kontrendike ise APKC uygulanmalıdır. Buna, hasta mobilize olana kadar devam edilmelidir.

\section{Pelvis, kalça ve proksimal femur kırıkları}

> VTE riski kanama riskinden yüksek olan, pelvis, kalça veya proksimal femur kırıklı olgularda, VTE profilaksisi için bir ay süre ile aşağıdakilerden biri uygulanabilir.

- DMAH: ameliyattan 6-12 saat sonra başlanmalıdır.

- Fondaparinuks sodyum: ameliyattan altı saat sonra başlanmalıdır.

Hastanın başvuru anından sonraki günlerde ameliyatı gerçekleştirilecek pelvis, kalça veya proksimal femur kırıklı olgular için, cerrahi öncesi dönemde VTE profilaksisi uygulanmalıdır. Son doz, eğer DMAH uygulanıyorsa ameliyat başlangıcından önceki 12. saatte, fondaparinuks sodyum uygulanıyorsa ameliyattan önceki 24 . saatte yapılmalıdır.

Pelvis, kalça veya proksimal femur kırı̆̆ı nedeniyle başvuran, farmakolojik profilaksi uygulanması kontrendike olan olgularda, APKC uygulanmalıdır. Buna, kişi normal veya beklenen hareketliliğine ulaşana kadar devam edilmelidir.

\section{Artroplasti dışı ortopedik diz cerrahisi}

> Toplam anestezi süresi 90 dk'dan az, düşük VTE riski olan artroskopik diz cerrahisi geçiren hastalar için VTE profilaksisi gerekli değildir.

> Toplam anestezi süresi $90 \mathrm{dk}$ 'dan fazla veya VTE riski kanama riskinden fazla olan, artroskopik diz cerrahisi geçiren olgular için, 14 gün boyunca, ameliyattan 6-12 saat sonra başlanarak DMAH uygulanabilir.
VTE riski kanama riskinden fazla olan, diğer diz ameliyatlarından birini (örn.; osteotomi veya kırık ameliyatı) geçiren olgular için VTE profilaksisi uygulanabilir.

VTE riski kanama riskinden fazla olan, alt ekstremite immobilizasyonu gerektiren olgular için, DMAH veya fondaparinuks sodyum ile farmakolojik VTE profilaksisi uygulanabilir. Alt ekstremite immobilizasyonu 42 günden fazla devam ederse profilaksi durdurulmalıdır.

\section{Ayak ve ayak bileği cerrahisi}

Ayak veya ayak bileği ameliyatı geçiren olgularda farmakolojik VTE profilaksisi gerekebilecek durumlar şunlardır:

- Toplam anestezi süresinin 90 dk'dan fazla olması.

- Olgunun VTE riskinin kanama riskinden daha fazla olması.

- İmmobilizasyon gerektiren cerrahi (örn.; artrodez veya artroplasti) sonrası başlanan profilaksi, immobilizasyon 42 günden daha uzun sürerse durdurulmalıdır.

\section{Üst ekstremite cerrahisi}

Üst ekstremite ameliyatı için lokal veya bölgesel anestezi uygulanıyorsa, VTE profilaksisi genellikle gerekli değildir.

Hastanın genel anestezi altında geçirdiği süre 90 dk'dan fazlaysa veya ameliyatın mobilizasyonu zorlaştırması muhtemel ise, üst ekstremite ameliyatı geçiren kişiler için VTE profilaksisi uygulanmalıdır.

\section{Elektif spinal cerrahi}

Elektif omurga cerrahisi planlanan hastalarda; aşağıdaki mekanik VTE profilaksisi yöntemlerinden birisi, 30 gün boyunca veya kişi mobil olana kadar uygulanmalıdır.

- Anti-embolik çoraplar.

- APKC.

Hasta ve planlanan cerrahiye ait faktörler göz önünde bulundurularak, VTE riski kanama riskinden fazla olan ve spinal cerrahi planlanan hastalarda, DMAH ile farmakolojik VTE profilaksisi uygulanmalıdır. 
Elektif omurga cerrahisi planlanan hastalar için DMAH kullanılacaksa; buna, hastanın özellikleri ve cerrahi süreç dikkate alınarak, ameliyattan 2448 saat sonra başlanmalı, 30 gün boyunca veya kişi mobil olana kadar devam edilmelidir.

Elektif spinal cerrahi geçiren kişiler için DMAH profilaksisine, cerrahın görüşü alınarak, gerekirse ameliyattan 24 saatten daha erken de başlanabilir.

\section{SONUÇ}

Venöz tromboemboliye bağlı gelişen yüksek morbidite ve mortalite, günümüzde farmakolojik profilaksi ajanlarının, bu ajanların kullanım süresi ve olgu temelli yaklaşım prensiplerinin ve non-farmakolojik profilaksi yöntemlerinin gelişmesi ile, gün geçtikçe azalmaktadır. Bununla beraber, bazı hastalarda kanamaya yatkınlık olması, farmakolojik profilaksiye karşı kontrendike durumların mevcudiyeti, profilaksinin süresi gibi 'gri alanlar', standardizasyon zorluğu yaratmaktadır. Dolayısıyla, ACCP, AAOS ve NICE gibi popüler kılavuzlar dışında, Avustralya, İskoçya ve ülkemizin de arasında bulunduğu de pek çok ülke, kendi VTE kılavuzlarını yayımlamıştır. Bu kılavuzlar genel hatları ile birbiriyle örtüşmekle birlikte, en dikkat çekici farklılık, asetilsalisilik asit kullanımına yöneliktir. En güncel kılavuz olan NICE kılavuzu, diz artroplastisi sonrası tek başına asetilsalisilik asit kullanımını da önermektedir. Buna karşın, önceki kılavuzlarda böyle bir öneri bulunmamaktadır. Dolayısıyla, en eski farmakalojik ajan olan asetilsalisilik asite yönelik önerilerin dahi değişmekte olması profilaksi prensiplerinin oturduğu zeminin ne derece kaygan ve değişime açık olduğunu göstermektedir. Cerrahi süresi, cerrahi içinde bacağı uygun pozisyonda tutma, intramedüller yıkama, ameliyat sonrası çok erken hareket verebilme ve cerrahi tekniğin gelişmesinin VTE riskini azaltıp farmakolojik profilaksi yöntemini değiştirdiği ve değiştireceği unutulmamalıdır. Literatürde kanıt düzeyi yüksek çalışmaların sayısı arttıkça, yeni farmakolojik ve non-farmakolojik profilaksi yöntemlerinin etkileri ve yan etkileri açıklığa kavuştukça, 'gri alanlar' daralacak ve VTE'nin neden olduğu morbidite ve mortalite azalacaktır.

\section{KAYNAKLAR}

1. Falck-Ytter Y, Francis CW, Johanson NA, Curley C, Dahl OE, Schulman S, Ortel TL, Pauker SG, Colwell CW Jr.. Prevention of VTE in orthopedic surgery patients: Antithrombotic Therapy and Prevention of Thrombosis, 9th ed. American College of Chest Physicians EvidenceBased Clinical Practice Guidelines. Chest 2012;141(2 Suppl):e278S-325S. Crossref

2. Pedersen AB, Sorensen HT, Mehnert F, Overgaard S, Johnsen SP. Risk factors for venous thromboembolism in patients undergoing total hip replacement and receiving routine thromboprophylaxis. J Bone Joint Surg Am 2010;92(12):2156-64. Crossref

3. Zhang J, Chen Z, Zheng J, Breusch SJ, Tian J. Risk factors for venous thromboembolism after total hip and total knee arthroplasty: a meta-analysis. Arch Orthop Trauma Surg 2015;135(6):759-72. Crossref

4. Jacobs JJ, Mont MA, Bozic KJ, Della Valle CJ, Goodman SB, Lewis CG, Yates ACJ, Boggio LN, Watters WC, Turkelson CM, Wies JL, Sluka P, Hitchcock K. American Academy of Orthopaedic Surgeons clinical practice guideline on: preventing venous thromboembolic disease in patients undergoing elective hip and knee arthroplasty. J Bone Joint Surg Am 2012;94(8):746-7. Crossref

5. Guyatt G, Gutterman D, Baumann MH, Addrizzo-Harris D, Hylek EM, Phillips B, Raskob G, Lewis SZ, Schünemann H. Grading strength of recommendations and quality of evidence in clinical guidelines: report from an American College of Chest Physicians Task Force. Chest 2006;129(1):174-81. Crossref

6. National Institute for Health and Clinical Excellence. Venous thromboembolism in over 16s: reducing the risk of hospital-acquired deep vein thrombosis or pulmonary embolism, 2018. Available at: https://www.nice.org.uk/ guidance/ng89 